DEMOGRAPHIC RESEARCH

VOLUME 36, ARTICLE 40, PAGES 1185-1208

PUBLISHED 12 APRIL 2017

http://www.demographic-research.org/Volumes/Vol36/40/

DOI: 10.4054/DemRes.2017.36.40

Research Article

\title{
Changes in economic activity: The role of age and education
}

\section{Elke Loichinger}

\section{Alexia Prskawetz}

(c) 2017 Elke Loichinger \& Alexia Prskawetz.

This open-access work is published under the terms of the Creative Commons Attribution NonCommercial License 2.0 Germany, which permits use, reproduction \& distribution in any medium for non-commercial purposes, provided the original author(s) and source are given credit. See http://creativecommons.org/licenses/by-nc/2.0/de/ 


\section{Contents}

1 Introduction 1186

2 Method 1188

2.1 Decomposing the change in the overall labor force participation 1189

2.2 Decomposing the change in age-specific labor force participation 1190

3 Data 1192

$4 \quad$ Results 1192

4.1 Decomposition of the overall labor force participation 1193

4.2 Decomposition of age-specific labor force participation 1196

$5 \quad$ Discussion and conclusion $\quad 1201$

6 Acknowledgments $\quad 1202$

$\begin{array}{ll}\text { References } & 1203\end{array}$

$\begin{array}{lr}\text { Appendix } & 1205\end{array}$ 


\title{
Changes in economic activity: The role of age and education
}

\author{
Elke Loichinger ${ }^{1}$
}

Alexia Prskawetz ${ }^{2}$

\begin{abstract}
BACKGROUND

Between 2000 and 2010, the labor force participation of European men stayed mostly constant, whereas the participation of women continued to increase. Participation rates of people close to normal retirement ages rose almost universally. At the same time, the education composition shifted toward higher levels of educational attainment and education-specific differentials in economic activity persisted.
\end{abstract}

\section{OBJECTIVE}

The aim of the paper is to understand the extent to which developments of labor force participation rates between 2000 and 2010 in selected European countries can be explained by age-specific and education-specific changes in participation rates, as compared to changes in populations' structural composition by age and education.

\section{METHODS}

We apply a decomposition methodology that allows us to disentangle changes in age- and education-specific labor force participation rates from changes in the age and educational structure of the population.

\section{RESULTS}

Our results show that labor force participation rates of adult women would have increased even more, had it not been for the downward pressure from the shift in the age composition toward older age groups with relatively lower levels of participation. This downward pressure also depressed male participation. The increase in participation among older people is mainly explained by participation increases among those with non tertiary education and is reinforced by a general shift toward higher levels of educational attainment.

\section{CONCLUSIONS}

Beyond changes in the age structure, we quantify the role of compositional changes by

\footnotetext{
${ }^{1}$ College of Population Studies, Chulalongkorn University, Bangkok, Thailand, E-Mail: Elke.L@ @hula.ac.th.

2 Technische Universität Wien and Wittgenstein Centre for Demography and Global Human Capital (IIASA, VID/OEAW, WU), Austria.
} 
educational attainment. Our results indicate that labor supply may not decrease to the extent expected due to population aging, given educational expansion and educationspecific patterns of economic activity.

\section{Introduction}

Developments of labor supply and labor force participation in Europe have been widely analyzed recently, not least because of the expected decline in the number of workers in the future due to the shift in the populations' age composition toward older ages (see, e.g., Carone 2005; Balleer, Gómez-Salvador, and Turunen 2009). If economic activity levels remain at current levels while the share of the non working population increases significantly during the next decades as predicted, problems are anticipated, particularly for social security systems that rely on pay-as-you-go schemes.

The potential to increase labor supply is mainly argued to come from women and older people, since their labor market involvement is lower than that of adult men (European Commission 2014). It is in precisely these two groups where increases in participation can be observed in the last decade: Whereas participation of men of prime ages was predominantly constant at high levels in all countries or decreased slightly, participation of adult women continued to increase in most countries. When it comes to female labor force participation, the forerunners are the Scandinavian and Baltic countries, Iceland, and most Eastern European countries, where larger shares of women entered the labor force significantly earlier than in other parts of Europe. Participation rates of people close to normal retirement ages, on the other hand, have been on the rise in every country since around the year 2000, with very few exceptions (cf. Figure A-1 in the Appendix). Consequently, in these countries, labor forces contain higher shares of women than in the past, and the participant population is slowly growing older.

Much less attention has been given to the fact that - in addition to changes in the sex and age composition of the labor force - the education composition of the active population has changed. As increasing shares of people within each birth cohort have attained higher education levels than the previous cohort, the education composition of the adult population has shifted toward higher degrees (Heckman and Jacobs 2010). The difference in percentage points in the proportion of younger adults (25-34 years) and older adults (55-64 years) with a tertiary degree amounts, for example in France, to $19.6 \%$ for men and $29.0 \%$ for women. The respective values are, in the Slovak Republic $5.3 \%$ and $18.2 \%$, in Denmark $5.1 \%$ and $16.8 \%$, and in Italy $5.1 \%$ and $15.2 \%$ (OECD 2013).

Another not much covered fact is that the level of educational attainment and the level of labor force participation are positively correlated in Europe. This effect is stronger 
for women than for men and larger among those aged 50+ than for middle-aged workers (cf. Figure 1). Also, the higher the education level, the smaller the differences between male and female participation rates (Loichinger 2015). Employment rates are highest for people with tertiary education, whereas their unemployment rates are consistently lower than for those with less educational attainment (OECD 2013), which is an indicator of the continued demand for workers with higher education and special skills.

Figure 1: $\quad$ Education-specific labor force participation rates (in \%), EU28, by age groups and sex, 2013
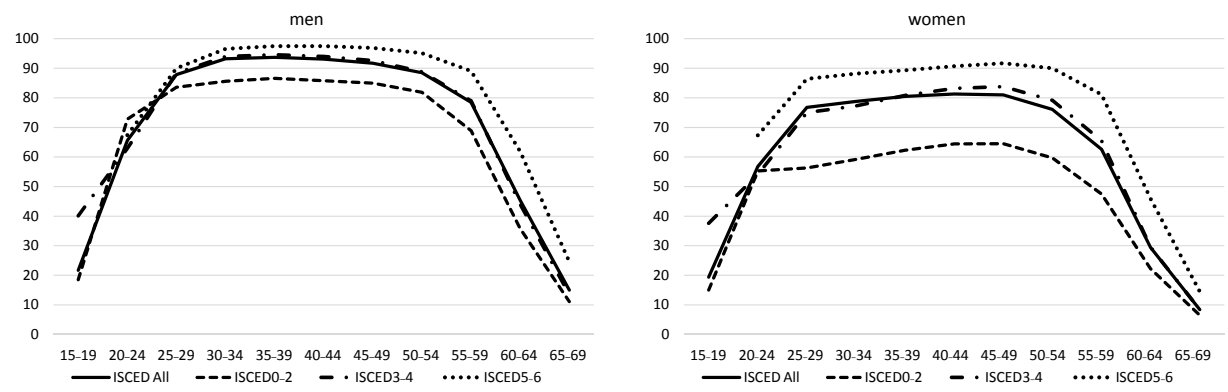

Source: Eurostat database, LFS-based.

Note: ISCED 0-2: pre-primary, primary, and lower secondary education; ISCED 3-4: upper secondary and post secondary non tertiary education; I SCED 5-6: first and second stage of tertiary education.

Against this backdrop - changes in the education structure of the population and the existence of education-specific differentials in economic activity - the question arises: How much of each of the observed past changes in labor force participation is due to changes in the educational composition (i.e., the shift toward educational groups with higher labor force participation rates) versus the change in education-specific labor force participation rates themselves. Disentangling these two effects is the focus of this paper. Burtless (2013) has shown for the United States that slightly more than half of the observed increase in participation of 60- to 74-year-old men between 1985 and 2010 was due to increases in educational attainment, and only a third due to the increases in participation rates. ${ }^{3}$

Our approach is in the spirit of Prskawetz et al. (2005), who quantified for selected countries how much of the change in the crude labor force participation rate between the mid-1980s and 2000 was due to changes in the age composition of populations and how much to changes of age-specific activity rates. They showed for France, West Germany,

\footnotetext{
${ }^{3}$ The remainder was explained by a shift toward younger ages - meaning on average higher participation rates - within the age group 60-74 between 1985 and 2010.
} 
Spain, the United Kingdom, and the United States that observed increases in the female crude labor force participation rates between the years 1985 and 2000 can be explained by increases in age-specific participation rates. Changes in the age composition of these countries' populations played only a very minor role, and the effect that these changes did have was positive and reinforced the overall increase. Similarly, the observed decline in male participation during the same period was also mainly due to changes in age-specific labor force participation rates. Here, the overall decline would have been even larger for Spain, the United Kingdom, and the United States if the growth rate of the population in age groups with high participation had not been positive.

We are curious whether the findings from Prskawetz et al. (2005) still hold true for a later time period or whether the relative importance of effects changed. Since the data situation allows us to do so, we include a larger number of countries than the original analysis. ${ }^{4}$ The reason to focus on European countries is mostly data-driven: Harmonized labor force and education data for European countries can be obtained from Eurostat. By adding more countries, we will be able to paint a broader picture across Europe in terms of the relative importance of changes in the age and education composition of countries' populations.

Our analysis will cover 14 European countries and be done separately for women and men. We start by describing the methodological foundation of our approach. Next, we describe our data and explain the selection of countries and age groups that enter the analysis. In the results section, we first apply the decomposition presented in Prskawetz et al. (2005) to a larger number of EU countries and a more recent time than in the original publication. This allows us to select the age groups that contributed the most to observed changes in crude labor force participation between 2000 and 2010. In a next step, we disentangle the change in labor force participation for these age groups in the contribution of changes in education-specific participation and in the educational composition of the population. Additionally, we split both effects by educational level. Finally, we discuss our findings and evaluate the implications for future developments of labor force participation.

\section{Method}

Standardization is a common tool in demography to eliminate the role of compositional effects when comparing demographic indicators between countries or over time. However, the choice of a standard population is not clear cut. As an alternative, a decom-

\footnotetext{
${ }^{4}$ The countries included are Belgium, Czech Republic, Denmark, Finland, France, Greece, Hungary, Italy, Netherlands, Portugal, Slovakia, Slovenia, Switzerland, and the United Kingdom. Other European countries are excluded due to breaks in the time series data for labor force participation and/or educational attainment. See section 3 for more details.
} 
position methodology can be applied which decomposes the change of a demographic indicator over time into a direct change of the characteristic of interest and a change due to the changing composition or structure of a population (see Canudas Romo 2003 for an excellent review).

We apply the decomposition methodology by Vaupel and Canudas Romo (2002) in several steps. First we decompose the change in overall labor force participation into an effect of changing age-specific labor force participation rates versus changes in the age composition of the population in order to quantify the magnitude of both effects. Next, we apply the same decomposition by 5 -year age groups to determine for which age group the labor force participation changed the most. For this specific age group, we disentangle in our third step the change in the labor force participation into an education-specific change in labor force participation versus a compositional effect of changing educational distributions. In a final step, we apply the decomposition by level of education to determine for which educational category the labor force participation changed the most.

\subsection{Decomposing the change in the overall labor force participation}

We restrict our analysis of changes in economic activity to ages 15-74 and call the corresponding rate the crude labor force rate defined as (cf. Prskawetz et al. 2005: 171 ff.):

$$
\bar{l}(t)=\frac{\int_{15}^{74} l(a, t) N(a, t) d a}{\int_{15}^{74} N(a, t) d a}
$$

where $l(a, t)$ denotes the fraction of people aged $a$ at time $t$ in the labor force, and $N(a, t)$ denotes the number of people aged $a$ at time $t$. The crude labor force rate gives the expected value of the age-specific labor force participation rate $l(a, t)$ with the weighting function $\frac{N(a, t)}{\int_{15}^{75} N(a, t) d a}$.

We can apply the formula by Canudas Romo (2003) which gives the change of the average over time as a sum of the direct (level 1) and compositional (level 2) effect:

$$
\dot{\bar{l}}=\overline{\dot{l}}+\operatorname{Cov}_{N}(l, \dot{N})
$$

The subscript $N$ denotes the weighting function and $N$ denotes the age-specific population growth rate (relative change): $N=\frac{\frac{\partial}{\partial t} N(a, t)}{N(a, t)}$. The first term on the right side 
of equation (2) $\bar{i}$ captures the direct effect, i.e., the average change in age-specific labor force participation rates. This term may be positive or negative depending on whether the labor force participation rates in specific age groups have increased or decreased over time. The sign of the first term (the average of the time derivative) will depend on the changes in the involved age groups and on the size of the involved age groups. The second term relates to the compositional change, i.e., changes in the age composition of the population over time.

Like Prskawetz et al. (2005: 175), we can apply formula (2) to 5-year age groups:

$$
\dot{\bar{l}}=\left[\bar{l}+\operatorname{Cov}_{N}(l, N)\right]_{15}^{19}+\ldots .+\left[\bar{l}+\operatorname{Cov}_{N}(l, N)\right]_{70}^{74}
$$

The covariance term will include the mean of the labor force participation rates and the mean of the age-specific growth rates and is therefore a function of all age groups. This formula allows us to estimate the contribution of the direct and compositional change to the age-specific change in the crude labor force rate.

\subsection{Decomposing the change in age-specific labor force participation}

While in the previous section we decomposed the labor force participation rate by age, we are now focusing on a decomposition of the labor force by education. To avoid mixing up the age and educational compositional effect, we investigate the role of educational changes for age-specific labor force participation rates.

We therefore apply the same decomposition methodology as in the previous section, now turning our attention to education instead of age. The goal with this analysis is to disentangle the change in age-specific labor force participation into a direct effect that captures any shifts in the education-specific labor force participation rates over time versus the effect of shifts in the educational composition toward educational groups with lower or higher participation rates. We are therefore not just controlling for the educational distribution as done in standardization methods but are interested in determining to what extent a change in the educational distribution versus a change in education-specific labor force participation can explain observed changes in age-specific labor force participation.

We define age-specific labor force participation rates as the number of people of a specific age group belonging to the labor force divided by the population for the same age group:

$$
\bar{l}(a, t)=\frac{\int_{e_{l}}^{e_{u}} l(a, e, t) N(a, e, t) d e}{\int_{e_{l}}^{e_{u}} N(a, e, t) d e}
$$


where $l(a, e, t)$ denotes the fraction of people in age group $a$, education group $e$, at time $t$ who participate in the labor force, the variable $N(a, e, t)$ denotes the number of people in age group $a$, education group $e$, at time $t$, and $e_{l}, e_{u}$ are the lowest and highest levels of education of the labor force. The labor force participation rate at age $a$ is therefore the mean of the education-specific labor force participation rate with $N(a, e, t) / \int_{e_{l}}^{e_{u}} N(a, e, t) d e$ being the weighting function.

For each age group, we can apply a decomposition methodology similar to that used in the previous section, with the educational level representing the compositional variable. We decompose the change in the age-specific labor force $l(a, t)$ into the direct (level 1) and compositional (level 2) effect:

$$
\dot{\bar{l}}(a)=\overline{\dot{l}}(a)+\operatorname{Cov}_{N}\left(l(a), N^{\prime}(a)\right)
$$

The subscript $N$ denotes the weighting function and $N(a)$ denotes the education specific growth rate (relative change) for age $a: N(a)=\frac{\frac{\partial}{\partial t} N(a, e, t)}{N(a, e, t)}$. The first term $\bar{i}(a)$ captures the direct effect, i.e., the average change in education-specific labor force participation rates within the age group considered. This education-specific term may be positive or negative depending on whether the labor force participation rates in specific educational groups have increased or decreased over time. The sign of the first term (the average of the time derivative) will depend on the changes in the involved educational groups. The second term relates to the compositional change, i.e., changes in the educational composition over time.

To gain insight into the contribution of each education level to the total change of age-specific labor force over time we can - as in equation (3) - decompose our formula in equation (5) into education-specific components (assuming, e.g., three levels of education):

$$
\begin{array}{r}
\dot{\bar{l}}(a)=\left[\overline{\dot{l}}(a)+\operatorname{Cov}_{N}\left(l(a), N^{\prime}(a)\right)\right]_{e_{1}}+\left[\overline{\dot{l}}(a)+\operatorname{Cov}_{N}\left(l(a), N^{\prime}(a)\right)\right]_{e_{2}}+ \\
{\left[\overline{\dot{l}}(a)+\operatorname{Cov}_{N}\left(l, N^{\prime}(a)\right)\right]_{e_{3}}}
\end{array}
$$

Such a decomposition by educational level allows us to quantify the role of each educational group in explaining the overall change in age-specific labor force participation rates. The education-specific compositional effect is, however, rather difficult to explain since the covariance will depend on the mean of the labor force participation rates and the mean of the education-specific growth rates and therefore depends on all education groups. 


\section{Data}

Country-specific data for labor force participation and population composition - by age, sex, and highest level of educational attainment - are based on the European Labor Force Survey (EU LFS) and are available for 33 countries. ${ }^{5}$ The selection of countries, years, as well as age groups of analysis is driven by methodological considerations (as explained in the next section), the availability of data, and the results of each step of our analysis.

The definition of labor force participation is based on the definition of the International Labour Organization (ILO) and is composed of the employed and unemployed (ILO 1982). Data by educational attainment based on the International Standard Classification of Education (ISCED) 1997 have been part of the EU LFS since 1998 and thus define the earliest point in time for any education-specific analysis. The three categories for which the highest level of completed educational attainment is provided by are 1) preprimary, primary, and lower secondary education (ISCED levels 0, 1, and 2), 2) upper secondary and postsecondary nontertiary education (ISCED levels 3 and 4), and 3) first and second stage of tertiary education (ISCED levels 5 and 6) (UNESCO 2006). There are, however, sometimes severe breaks in the time series of the labor force as well as education data due to countries' changes in the translation of the guidelines for economic activity and educational attainment or changes in the overall sampling procedure. ${ }^{6}$ In instances where these breaks introduced noticeable jumps in countries' time-series trajectories, countries were excluded completely from the analysis.

A general consideration is the width of age groups that we analyze. On the one hand, participation patterns over time are more stable for broader age groups. On the other hand, changes in the age structure within broader age groups (e.g., ages 60-74) also affect the aggregate participation rates of these age groups over time. Burtless (2013) points this out and quantifies this nonnegligible effect for the United States. We opted therefore for the analysis of 5-year age groups, being aware that this decision restricts the pool of possible countries further, since labor force participation by educational attainment and 5-year age groups is not continuously available in all countries, particularly for women in older age groups.

\section{Results}

We show results for our two decomposition analyses, each one involving two steps: First, we repeat the analysis in Prskawetz et al. (2005), including more countries and covering a more recent time period. Besides decomposing changes in crude labor force participation

\footnotetext{
${ }_{5}^{5}$ All data are available online at http://ec.europa.eu/eurostat/data/database.

6 For details see http://ec.europa.eu/eurostat/statistics-explained/index.php/EU_labour_force_survey_methodology.
} 
in a participation and age composition effect, this analysis returns the 5-year age group that contributed the most on average to the observed change in overall participation.

Second, we present the contribution of education-specific changes in participation, and in the educational composition of the population, on changes in labor force participation for the age group identified in the first step. Finally, we show how much of the overall observed change in age-specific labor force participation is due to changes of labor force participation in each of the three educational levels.

\subsection{Decomposition of the overall labor force participation}

As explained in Vaupel and Canudas Romo (2002) and also discussed in the appendix of Prskawetz et al. (2005), we assume that the rate of change is more or less constant over the time interval we chose for the analysis of our labor force indicators. We therefore start with visually inspecting the development of crude labor force rates by sex, starting in 1998, and include only the countries and time periods where the assumption of a linear change is valid for both men and women. This reduces the period of analysis to the years 2000 to 2010 and the number of countries to 14: Belgium, Czech Republic, Denmark, Finland, France, Greece, Hungary, Italy, Netherlands, Portugal, Slovakia, Slovenia, Switzerland, and the United Kingdom.

Figures A-3 and A-4 in the appendix show the development of the labor force participation rate of 15- to 74-year-old women and men between 1998 and 2013. With the exception of the Czech Republic, Denmark, Finland, and Slovakia - where participation stayed about constant - the trend of increasing female participation continued between 1998 and 2013, and differences in participation levels in the 14 analyzed countries declined. The picture of male participation is more diverse: Whereas participation remained pretty stable in 9 out of the 14 countries, it decreased slightly in Denmark, Finland, and Switzerland and increased marginally in Hungary and Slovenia.

Still, in 2013, the range of participation rates remains significantly larger for women than for men, despite the mentioned decline in the differences in female participation during the preceding 15 years. In general, a wide range of micro- and macro-level factors have been analyzed in the attempt to explain differences in female labor force participation across countries (Steiber and Haas 2012). In the European context, recent analyses support previous findings: A positive attitude toward working women, educational attainment, as well as the number of children are important determinants on the individual level, whereas policies related to taxation of the second earner, lump sum family allowance cash transfers, and spending on childcare and early child education matter on the policy level (Christiansen et al. 2016). These institutional factors and differences in female labor market attachment are associated with countries' differences in their welfare states. According to Esping-Andersen (1990), there are three main types of welfare state 
regimes that can all be found in Europe: a liberal regime (e.g., in the United Kingdom), a social democratic regime (e.g., in Denmark), and a corporatist welfare regiume (e.g., in France and Italy).

The results in Table 1 confirm the visual inspection: Female labor force participation increased in 9 out of 14 countries between 2000 and 2010, and in those cases where it declined, the decrease was small. ${ }^{7}$ The question is to what degree these observed patterns are the result of changes in age-specific participation (column 6 in Tables 1 and 2) or in the age composition of populations (column 7). Except for Greece, the age-structure effect has turned negative for women. Still, the overall observed increase in participation was only relatively little attenuated by the negative effect of changes in the age composition, which means that the overall change in participation is still dominated by the development of age-specific participation. Only in four countries - the Czech Republic, Denmark, Finland, and Portugal - is the relative size of the age-structure effect larger than the participation effect. Furthermore, in Denmark and Finland, the participation effect is positive, but due to the larger age-structure effect, the overall change in participation is negative. However, one has to bear in mind that these are the two countries where female labor force participation is among the highest of all 14 countries.

The results for men warrant a more nuanced interpretation. In contrast to the female case, the participation effect dominates in only 6 out of 14 countries. This means that the negative population growth in age groups with high participation entails on average a lower increase in overall participation than in the absence of these structural changes. For Hungary and Slovakia, the flat profile of males in Figure A-4 is the combination of a participation effect and a population structure effect that cancel each other out. Both effects are small though. In the Czech Republic, Italy, and Switzerland, the observed decline in overall participation was a combination of both a decrease in age-specific participation and a shift of the population structure toward age groups with lower levels of economic activity. In Denmark, the small but positive participation effect is outweighed by a relatively large negative age effect. In the Netherlands, on the other hand, a large negative age effect is more than compensated by the largest positive participation effect observed for men in any country. At a lower level, the same applies to Belgium and France. Slovenia is the only country where both effects are positive.

What should come as no surprise is that the country-specific age effect is much more similar between men and women than the participation effect. On the one hand, female and male populations of working age are for the most part of about equal size and structure in the countries under consideration, unless migration differs noticeably

\footnotetext{
${ }^{7}$ Column 5 in Tables 1 and 2 represents the change in crude labor force rate at midyear (2005). We use the formula presented in the appendix in Prskawetz et al. (2005) to apply the continuous formulas from section 2 to discrete data, based on the assumption that changes occur continuously over time. The validity of this assumption can be tested by comparing the values in column 5 and 8, i.e., by comparing the calculated change at midyear with the summation of the two separate effects.
} 
by sex. On the other hand, economic activity is more volatile compared to population development per se and differences in patterns of economic activity between men and women add to that as well.

Table 1: Crude labor force participation rate for women, ages 15-74, per thousand, and the decomposition of the change over time from 2000 to 2010

\begin{tabular}{lccccrcc}
\hline Country & $\overline{\mathbf{l}}(2000)$ & $\overline{\mathbf{l}}(2010)$ & $\overline{\mathbf{l}}(2005)$ & $\dot{\overline{\mathbf{l}}}(2005)$ & $\overline{\mathrm{i}}$ & $\operatorname{Cov}_{\mathbf{N}}(\mathbf{l}, \mathbf{N})$ & $\dot{\overline{\mathbf{l}}}=\overline{\dot{\mathrm{i}}}+\mathbf{C o v}_{\mathbf{N}}(\mathbf{l}, \mathbf{N})$ \\
\hline Belgium & 487.4 & 545.7 & 511.1 & 5.8 & 6.0 & -0.5 & 5.5 \\
Czech Republic & 559.1 & 543.3 & 546.4 & -1.6 & -0.4 & -1.2 & -1.6 \\
Denmark & 672.6 & 666.7 & 667.8 & -0.6 & 2.1 & -2.9 & -0.8 \\
Finland & 650.8 & 637.2 & 638.0 & -1.4 & 0.9 & -2.6 & -1.6 \\
France & 545.0 & 587.7 & 564.2 & 4.3 & 5.0 & -0.8 & 4.2 \\
Greece & 439.0 & 502.2 & 466.3 & 6.3 & 5.1 & 1.2 & 6.3 \\
Hungary & 455.6 & 488.3 & 465.2 & 3.3 & 4.1 & -1.0 & 3.1 \\
Italy & 399.7 & 441.1 & 415.1 & 4.1 & 4.2 & -0.1 & 4.1 \\
Netherlands & 589.0 & 663.3 & 621.0 & 8.2 & 10.9 & -2.8 & 8.1 \\
Portugal & 539.4 & 525.6 & 531.5 & -1.4 & 0.0 & -1.3 & -1.4 \\
Slovakia & 560.5 & 551.8 & 545.3 & -0.9 & -1.0 & -0.1 & -1.1 \\
Slovenia & 555.6 & 593.8 & 571.0 & 3.8 & 3.9 & -0.2 & 3.7 \\
Switzerland & 641.1 & 681.2 & 660.0 & 4.0 & 4.6 & -0.6 & 4.0 \\
United Kingdom & 603.3 & 623.4 & 611.9 & 2.0 & 2.6 & -0.6 & 2.0 \\
\hline
\end{tabular}

Source: Eurostat database, own calculations.

Table 2: $\quad$ Crude labor force participation rate for men, ages 15-74, per thousand, and the decomposition of the change over time from 2000 to 2010

\begin{tabular}{lccccrcc}
\hline Country & $\overline{\mathrm{I}}(2000)$ & $\overline{\mathrm{l}}(2010)$ & $\overline{\mathrm{l}}(2005)$ & $\dot{\overline{\mathrm{I}}}(2005)$ & $\overline{\mathrm{i}}$ & $\operatorname{Cov}_{\mathbf{N}}(\mathbf{l}, \mathbf{N})$ & $\dot{\overline{\mathrm{l}}}=\overline{\mathrm{i}}+\operatorname{Cov}_{\mathbf{N}}(\mathbf{l}, \mathbf{N})$ \\
\hline Belgium & 654.4 & 660.5 & 654.7 & 0.6 & 1.3 & -0.8 & 0.4 \\
Czech Republic & 725.1 & 719.5 & 719.2 & -0.6 & -0.1 & -0.5 & -0.6 \\
Denmark & 762.9 & 742.1 & 749.4 & -2.1 & 0.7 & -3.3 & -2.6 \\
Finland & 722.3 & 690.6 & 701.5 & -3.2 & 0.0 & -3.3 & -3.2 \\
France & 672.4 & 675.7 & 672.5 & 0.3 & 2.0 & -1.7 & 0.3 \\
Greece & 691.9 & 700.5 & 694.8 & 0.9 & -1.9 & 2.8 & 0.9 \\
Hungary & 614.6 & 613.7 & 609.8 & -0.1 & 0.5 & -0.5 & 0.0 \\
Italy & 659.2 & 648.1 & 651.6 & -1.1 & -0.8 & -0.3 & -1.1 \\
Netherlands & 768.7 & 778.9 & 769.3 & 1.1 & 4.5 & -3.5 & 1.0 \\
Portugal & 666.8 & 671.5 & 667.4 & 0.5 & 0.6 & -0.2 & 0.4 \\
Slovakia & 706.3 & 707.0 & 701.1 & 0.1 & -1.0 & 1.0 & 0.0 \\
Slovenia & 658.2 & 691.3 & 673.5 & 3.3 & 2.9 & 0.4 & 3.3 \\
Switzerland & 829.2 & 811.6 & 820.0 & -1.8 & -0.5 & -1.3 & -1.8 \\
United Kingdom & 750.3 & 743.9 & 745.8 & -0.6 & 0.4 & -1.0 & -0.7 \\
\hline
\end{tabular}

Source: Eurostat database, own calculations.

As described in the methods section equation (3), the decomposition into participa- 
tion and age-structure effects can be broken down further into age-group-specific components. Applying this decomposition to the 14 countries of our analysis reveals that for women, change in participation between 2000 and 2010 was largest for ages 55-59 in seven countries, followed by four countries where it peaked at age group 50-54. The lowest age group with the maximum change was observed in Greece (45-59), whereas the highest peak age group was in Finland and Switzerland (60-64). For men, peak change occurred among 55- to 59-year-olds in seven countries and for 60- to 64-year-olds in six countries. In the United Kingdom, 65- to 69-year-olds had the largest change. ${ }^{8}$ As an example, Figure 2 shows the age- and sex-specific results for France. ${ }^{9}$ For the subsequent analysis of education effects, we use each country's age group with the maximum change.

Figure 2: $\quad$ France: Age-group-specific contribution to participation effect, by sex, between 2000 and 2010

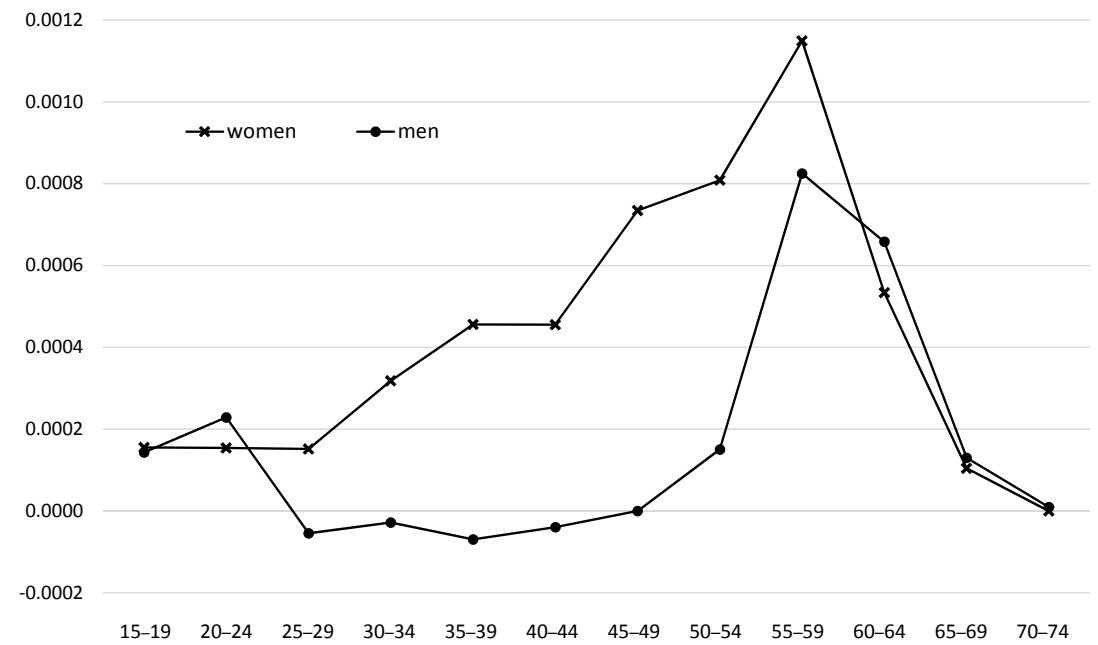

Source: Eurostat database, own calculations.

\subsection{Decomposition of age-specific labor force participation}

Denmark and the United Kingdom are dropped from the pool of 14 countries in the previous analysis due to methodological changes in their LFS that bias the analysis of their

\footnotetext{
${ }^{8}$ Country-specific information about which age group showed the maximum change is included after each country name in Table 4 and Table 5.

${ }^{9}$ Figures for all other countries are available upon request.
} 
education data over time. We chose to show results for the development of educational attainment of the 55- to 59-year-old population, since this is the age group where the greatest change in the labor force participation took place in the majority of countries. For men as well as women, educational attainment clearly shifted toward higher degrees since 2000 (cf. Figure A-2 in the Appendix). Changes in the education structure are happening more rapidly among women than among men, as the steeper slope for all three education groups indicates. Female advancement is especially pronounced for the tertiary education group, from $10.3 \%$ in 2000 to $16.5 \%$ in 2010, representing a relative increase of more than 50\%. In 2010, among men, those with at most lower secondary education (ISCED 0-2) no longer represent the largest education group but instead those with upper secondary and postsecondary nontertiary education (ISCED 3-4) hold the largest share, a transition that has yet to happen for women.

There are of course significant differences among countries when it comes to the educational attainment structure of their older population (cf. Table 3). The share of 55to 59-year-old men and women with at most lower secondary education decreased in all countries, and the shares in the two higher education groups increased almost universally. The largest relative reduction in the share of people with ISCED 0-2 occurred in Hungary and Slovakia (for men and women), whereas the largest relative increase in the share of people with ISCED 5-6 took place in Portugal (men) and Greece (women).

The question we ultimately want to answer is how much these changes in the educational composition contributed to the observed developments in labor force participation. With the exception of Greece and Slovenia (minuscule negative composition effect for men), the education effect is positive in all instances for women as well as men (column 7 in Table 4 and Table 5). ${ }^{10}$ This means that the positive participation effect that appears for every country (column 6 in Table 4 and Table 5) is 'enhanced' by the compositional change in education, leading to an increase in participation rates that would have been smaller in the absence of changes in educational composition.

\footnotetext{
${ }^{10}$ Note that for the decomposition of age-specific labor force rates in Table 4 and Table 5, we use different age groups for different countries. The choice of the age groups is based on the criteria of the greatest change in labor force participation, cf. last paragraph in section 4.1.
} 
Loichinger \& Prskawetz: Changes in economic activity: The role of age and education

Table 3: $\quad$ Educational composition (\%) of population age 55-59 for 12 selected European countries, by sex, 2000 and 2010

\begin{tabular}{|c|c|c|c|c|c|c|c|}
\hline Country & Year & $\begin{array}{l}\text { Men } \\
\text { ISCED 0-2 }\end{array}$ & ISCED 3-4 & ISCED 5-6 & $\begin{array}{l}\text { Women } \\
\text { ISCED 0-2 }\end{array}$ & ISCED 3-4 & ISCED 5-6 \\
\hline \multirow[t]{2}{*}{ Belgium } & 2000 & 54.8 & 22.2 & 23.0 & 63.8 & 20.2 & 16.0 \\
\hline & 2010 & 41.8 & 30.0 & 28.3 & 43.6 & 30.4 & 26.0 \\
\hline \multirow[t]{2}{*}{ Czech Republic } & 2000 & 12.2 & 75.6 & 12.2 & 31.2 & 60.0 & 8.9 \\
\hline & 2010 & 6.9 & 78.5 & 14.6 & 21.1 & 69.6 & 9.3 \\
\hline \multirow{2}{*}{ Finland } & 2000 & 45.3 & 25.7 & 29.0 & 44.2 & 29.8 & 26.0 \\
\hline & 2010 & 27.2 & 42.8 & 30.0 & 23.2 & 43.1 & 33.6 \\
\hline \multirow{2}{*}{ France } & 2000 & 47.1 & 37.1 & 15.8 & 56.7 & 28.9 & 14.4 \\
\hline & 2010 & 37.0 & 43.9 & 19.1 & 45.7 & 35.3 & 19.0 \\
\hline \multirow[t]{2}{*}{ Greece } & 2000 & 66.1 & 21.1 & 12.8 & 75.4 & 19.2 & 5.4 \\
\hline & 2010 & 50.9 & 27.8 & 21.3 & 55.2 & 30.5 & 14.3 \\
\hline \multirow{2}{*}{ Hungary } & 2000 & 48.0 & 36.3 & 15.7 & 59.5 & 29.2 & 11.3 \\
\hline & 2010 & 17.5 & 65.9 & 16.6 & 29.3 & 54.4 & 16.3 \\
\hline \multirow[t]{2}{*}{ Italy } & 2000 & 69.3 & 23.1 & 7.6 & 77.5 & 16.9 & 5.6 \\
\hline & 2010 & 54.4 & 33.4 & 12.2 & 58.6 & 29.9 & 11.5 \\
\hline \multirow[t]{2}{*}{ Netherlands } & 2000 & 34.7 & 40.6 & 24.7 & 55.3 & 30.3 & 14.4 \\
\hline & 2010 & 30.6 & 37.1 & 32.3 & 43.7 & 34.1 & 22.1 \\
\hline \multirow[t]{2}{*}{ Portugal } & 2000 & 89.4 & 5.2 & 5.4 & 94.1 & (u) & 5.9 \\
\hline & 2010 & 82.4 & 8.4 & 9.2 & 82.8 & 6.4 & 10.8 \\
\hline \multirow[t]{2}{*}{ Slovakia } & 2000 & 20.3 & 69.1 & 10.6 & 43.8 & 48.5 & 7.6 \\
\hline & 2010 & 10.6 & 74.1 & 15.4 & 21.2 & 66.8 & 12.0 \\
\hline \multirow[t]{2}{*}{ Slovenia } & 2000 & 25.4 & 59.4 & 15.3 & 41.7 & 46.3 & 11.9 \\
\hline & 2010 & 20.7 & 66.0 & 13.3 & 33.0 & 49.8 & 17.2 \\
\hline \multirow[t]{2}{*}{ Switzerland } & 2000 & 16.8 & 49.6 & 33.6 & 33.5 & 57.3 & 9.1 \\
\hline & 2010 & 12.3 & 48.3 & 39.4 & 24.4 & 54.7 & 20.9 \\
\hline
\end{tabular}

Source: Eurostat database, LFS-based.

Note: Population data for ISCED 3-4 for 55- to 59-year-old Portuguese women in 2000 was not provided from Eurostat due to unreliability (u). The next earlier and later data points where data are available are 1997 and 2001, where the share of 55- to 59-year-old women with ISCED $3-4$ is estimated to be $2.9 \%$ and $3.2 \%$, respectively.

For women, the participation effect dominates significantly over the educational composition effect (cf. Table 4). In Belgium, Greece, Hungary, Italy, and Switzerland, the educational composition effect is responsible for $20 \%$ or more of the overall observed increase in female participation. As with women, the participation effect dominates also for men (cf. Table 5). The relative importance of the education effect is smaller though than for women, which is in line with the presented changes in educational composition in Figure A-2 and in Table 3. The exception is Hungary, where over 50\% of the increase in participation between 2000 and 2010 is due to the change in the education composition of 55- to 59-year-old men. 
Table 4: $\quad$ Labor force participation rate for women for specified age group, per thousand, and the decomposition of the change over time from 2000 to 2010 for 12 European countries

\begin{tabular}{|c|c|c|c|c|c|c|c|}
\hline Country & $\overline{\mathbf{l}}(2000)$ & $\overline{\mathbf{l}}(2010)$ & $\overline{\mathrm{l}}(2005)$ & $\dot{\overline{\mathrm{l}}}(2005)$ & $\overline{\mathrm{i}}$ & $\operatorname{Cov}_{\mathbf{N}}(1, \hat{N})$ & $\dot{\overline{\mathrm{l}}}=\overline{\mathrm{i}}+\operatorname{Cov}_{\mathbf{N}}(\mathbf{l}, \hat{\mathrm{N}})$ \\
\hline Belgium (50-54) & 488.5 & 698.5 & 590.6 & 20.9 & 15.6 & 5.5 & 21.1 \\
\hline Czech Rep. (55-59) & 322.0 & 602.1 & 442.7 & 27.6 & 25.4 & 2.3 & 27.7 \\
\hline Finland $(60-64)$ & 225.1 & 418.8 & 306.4 & 19.1 & 16.2 & 2.9 & 19.1 \\
\hline France $(55-59)$ & 462.0 & 613.9 & 532.7 & 15.1 & 13.7 & 1.5 & 15.1 \\
\hline Greece (45-49) & 546.2 & 700.2 & 620.7 & 15.4 & 11.1 & 4.4 & 15.5 \\
\hline Hungary (55-59) & 201.0 & 508.6 & 329.7 & 29.7 & 24.0 & 6.5 & 30.5 \\
\hline Italy $(50-54)$ & 412.2 & 577.6 & 490.5 & 16.5 & 10.8 & 5.8 & 16.6 \\
\hline Netherlands (55-59) & 392.4 & 611.4 & 492.3 & 21.7 & 18.6 & 3.2 & 21.9 \\
\hline Portugal (50-54) & 618.6 & 750.3 & 681.3 & 13.1 & 10.9 & 2.3 & 13.2 \\
\hline Slovakia (55-59) & 184.0 & 511.3 & 315.0 & 31.3 & 26.1 & 6.0 & 32.1 \\
\hline Slovenia (50-54) & 599.0 & 776.5 & 660.6 & 21.7 & 18.3 & 3.4 & 21.7 \\
\hline Switzerland $(60-64)$ & 339.1 & 463.0 & 396.7 & 12.3 & 9.8 & 2.6 & 12.4 \\
\hline
\end{tabular}

Source: Eurostat database, own calculations.

Table 5: $\quad$ Labor force participation rate for men for specified age group, per thousand, and the decomposition of the change over time from 2000 to 2010 for 12 European countries

\begin{tabular}{|c|c|c|c|c|c|c|c|}
\hline Country & $\overline{\mathbf{l}}(2000)$ & $\overline{\mathbf{l}}(2010)$ & $\overline{\mathbf{l}}(2005)$ & $\dot{\overline{\mathrm{I}}}(2005)$ & $\overline{\mathrm{i}}$ & $\operatorname{Cov}_{\mathbf{N}}(1, \hat{\mathbf{N}})$ & $\dot{\overline{\mathrm{l}}}=\overline{\mathrm{i}}+\operatorname{Cov}_{\mathbf{N}}(\mathbf{l}, \mathbf{N}$ \\
\hline Belgium (55-59) & 537.7 & 661.5 & 596.0 & 12.4 & 9.8 & 2.6 & 12.4 \\
\hline Czech Rep. (60-64) & 245.0 & 381.7 & 307.0 & 13.6 & 12.0 & 1.6 & 13.6 \\
\hline Finland (60-64) & 278.7 & 443.7 & 352.4 & 16.4 & 14.7 & 1.7 & 16.4 \\
\hline France $(55-59)$ & 584.9 & 692.6 & 637.3 & 10.8 & 9.4 & 1.4 & 10.8 \\
\hline Greece (55-59) & 720.6 & 749.3 & 732.7 & 2.9 & 3.2 & -0.3 & 2.8 \\
\hline Hungary (55-59) & 523.0 & 631.9 & 584.3 & 10.9 & 4.7 & 6.3 & 11.0 \\
\hline Italy (55-59) & 533.6 & 683.2 & 603.8 & 14.9 & 12.3 & 2.6 & 14.9 \\
\hline Netherlands (60-64) & 268.8 & 497.8 & 366.8 & 22.5 & 21.4 & 1.2 & 22.6 \\
\hline Portugal $(60-64)$ & NA & NA & NA & NA & NA & NA & NA \\
\hline Slovakia (55-59) & 655.5 & 810.2 & 733.7 & 15.4 & 13.3 & 2.2 & 15.5 \\
\hline Slovenia (55-59) & 445.0 & 617.2 & 522.6 & 17.2 & 17.5 & -0.4 & 17.1 \\
\hline Switzerland (60-64) & 641.1 & 696.8 & 663.7 & 5.6 & 4.5 & 1.0 & 5.5 \\
\hline
\end{tabular}

Source: Eurostat database, own calculations.

Note: Calculations for Portugal are not possible, since labor force data for ISCED 3-4 for Portuguese men aged 60-64 in 2000 was not provided from Eurostat due to unreliability (u).

Sensitivity analyses showed that the level 1 effect (i.e., the direct effect, $\bar{i}$ ) is significantly more affected by the selection of starting and ending years of the analysis than the level 2 effect (i.e., the compositional effect, $\left.\operatorname{Cov}_{N}(l, N)\right)$. The explanation is simple: Labor force participation rates are more volatile over time than the educational attainment structure. Whereas changes in the starting or ending year of the analysis can have nonnegligible effects on the average change in participation rates over time, educational attainment within each age group does not show any sudden jumps.

The previous analysis has identified the extent to which education-specific changes 
in participation on the one hand and changes in the educational composition of the population on the other hand were responsible for observed changes in participation for the selected age groups. Now, we take the decomposition one step further by analyzing how the observed change in participation (i.e., the level 1 effect) for these specific age groups can be allotted to participation changes in each of the three education levels (i.e., we apply the decomposition as shown in equation (6) and show only the education-specific change in the labor force participation rates in the following tables).

As Table 6 and Table 7 illustrate, increases in overall participation were mostly driven, on average over all countries, by increases in the middle education category, followed by increases in the lowest education group; however, there are country-specific as well as gender-specific differences.

Table 6: Contribution (\%) of each education level to changes in female labor force participation, for specified age groups, between 2000 to 2010

\begin{tabular}{llrrr}
\hline Age group & Country & ISCED 0-2 & ISCED 3-4 & ISCED 5-6 \\
\hline $50-54$ & Belgium & $57 \%$ & $22 \%$ & $21 \%$ \\
$55-59$ & Czech Republic & $24 \%$ & $66 \%$ & $10 \%$ \\
$60-64$ & Finland & $33 \%$ & $37 \%$ & $30 \%$ \\
$55-59$ & France & $47 \%$ & $43 \%$ & $11 \%$ \\
$45-49$ & Greece & $48 \%$ & $46 \%$ & $6 \%$ \\
$55-59$ & Hungary & $44 \%$ & $46 \%$ & $10 \%$ \\
$50-54$ & Italy & $61 \%$ & $32 \%$ & $7 \%$ \\
$55-59$ & Netherlands & $49 \%$ & $37 \%$ & $14 \%$ \\
$50-54$ & Portugal & $88 \%$ & $9 \%$ & $3 \%$ \\
$55-59$ & Slovakia & $26 \%$ & $65 \%$ & $9 \%$ \\
$50-54$ & Slovenia & $30 \%$ & $64 \%$ & $7 \%$ \\
$60-64$ & Switzerland & $38 \%$ & $55 \%$ & $7 \%$ \\
\hline
\end{tabular}

Source: Eurostat database, own calculations.

Table 7: $\quad$ Contribution (\%) of each education level to changes in male labor force participation, for specified age groups, between 2000 to 2010

\begin{tabular}{llrrr}
\hline Age group & Country & ISCED 0-2 & ISCED 3-4 & ISCED 5-6 \\
\hline $55-59$ & Belgium & $34 \%$ & $30 \%$ & $35 \%$ \\
$60-64$ & Czech Republic & $10 \%$ & $86 \%$ & $3 \%$ \\
$60-64$ & Finland & $38 \%$ & $26 \%$ & $36 \%$ \\
$55-59$ & France & $46 \%$ & $42 \%$ & $12 \%$ \\
$55-59$ & Greece & $24 \%$ & $40 \%$ & $36 \%$ \\
$55-59$ & Hungary & $45 \%$ & $51 \%$ & $4 \%$ \\
$55-59$ & Italy & $58 \%$ & $33 \%$ & $9 \%$ \\
$60-64$ & Netherlands & $38 \%$ & $38 \%$ & $24 \%$ \\
$60-64$ & Portugal & $\mathrm{NA}$ & $\mathrm{NA}$ & $\mathrm{NA}$ \\
$55-59$ & Slovakia & $29 \%$ & $62 \%$ & $9 \%$ \\
$55-59$ & Slovenia & $34 \%$ & $60 \%$ & $6 \%$ \\
$60-64$ & Switzerland & $-4 \%$ & $-2 \%$ & $107 \%$ \\
\hline
\end{tabular}

Source: Eurostat database, own calculations. 
For females in Finland, we observed an equal contribution to the change in the labor force participation rate across all three educational levels. In four countries (Belgium, Italy, Netherlands, and Portugal), the increase in the labor force participation was driven to a large extent by the contribution of the lowest educational group. For three countries (France, Greece and Hungary), the contributions of the lowest and middle education groups were very similar.

For men, we also found some heterogeneity in the role of the three educational groups in explaining changes in the labor force participation. For Belgium, Finland, Greece, and the Netherlands we found that all three educational groups contributed to a large extent to the change in age-specific labor force participation. In France and Hungary, the lowest and middle educational groups contributed a similar share to the change in the age-specific labor force participation, while in Italy the lowest educational group had the highest contribution. For Switzerland, our results indicate that the increase in male labor force participation can be explained solely by higher labor force participation rates in the highest educational group.

\section{Discussion and conclusion}

The aim of the paper was to understand the extent to which changes in the labor force participation in European countries over the period from 2000 to 2010 can be explained by age-specific and education-specific changes in the labor force participation rates as compared to changes in the composition of age and educational groups. We conducted our study in four steps. First, we disentangled the relative contribution of age-specific (level 1) as compared to age structure (level 2) effects to changes in the crude labor force participation rate between 2000 and 2010. Based on the results in the first step, we identified which age groups contributed most to the overall level 1 effect in each country. For the selected age groups, we applied in the third step a decomposition of the change in the labor force participation rate by education (i.e., we investigated to what degree changes in education-specific labor force participation rates, as compared to the educational composition, were responsible for increases in participation in these age groups). In a final step, we investigated the amount that particular education groups contributed to the age-specific change in the labor force participation rate.

Between 2000 and 2010, the participation effect is the driving force behind the observed increases in crude female labor force participation rates that happened in the majority of countries. The negative age compositional effect, however, had already begun to attenuate the increase, meaning that crude female labor force participation rates would have been even larger without shifts in the population's composition toward older age groups with relatively lower participation levels. For men, the picture is more mixed, but here also structural changes in the age composition started to put downward pressure on 
crude labor force participation rates. For men as well as women, the age groups where the largest increase in participation took place was among the 55- to 59-year-olds and the 60to 64-year-olds. Our decomposition by education indicates that this observed increase in labor force participation was mainly due to changes in education-specific labor force participation rates. The change in the educational composition toward higher educational levels reinforced these trends. ${ }^{11}$ A final decomposition by level of education showed that changes in participation rates of those with nontertiary education contributed considerably more to the observed increases in participation than did the participation rates of those with tertiary education.

Putting our results in perspective, what can be expected for the future? Since younger, higher educated cohorts will continue to replace older cohorts with lower levels of education, a positive education effect will - ceteris paribus - persist. This continuous shift to higher levels of education will happen with large certainty during the next 20 years, since the cohorts causing this upgrading in skill levels - i.e., those aged between 25 and 45 years today - have for the most part already finished their educational attainment. Hence, we may expect that the negative age compositional effect that depresses the overall labor force may be counteracted by higher labor force participation rates among females, the elderly, and most importantly also by those with higher education.

\section{Acknowledgments}

We would like to thank Wolfgang Lutz for valuable feedback. This research has received funding from the European Union's Seventh Framework Programme for research, technological development, and demonstration under grant agreement no. 613247.

\footnotetext{
11 The overall effect of the educational composition might however be underestimated since we combined the educational levels in three categories. Any shift in the distribution within categories will therefore not be accounted for.
} 


\section{References}

Balleer, A., Gómez-Salvador, R., and Turunen, J. (2009). Labour force participation in the Euro area: a cohort based analysis. Frankfurt/Main: European Central Bank. (ECB Working Paper No. 1049).

Burtless, G. (2013). Can educational attainment explain the rise in labor force participation at older ages? Chestnut Hill: Center for Retirement Research at Boston College. (Issue in Brief 13-13).

Canudas Romo, V. (2003). Decomposition methods in demography. [PhD Thesis]. Groningen: Rijksuniversiteit Groningen, Population Studies.

Carone, G. (2005). Long-term labour force projections for the $25 \mathrm{EU}$ member states: A set of data for assessing the economic impact of ageing. Brussels: European Commission, Directorate-General for Economic and Financial Affairs. (Economic Papers Nr. 235).

Christiansen, L., Lin, H., Pereira, J., Topalova, P., and Turk, R. (2016). Individual choice or policies? Drivers of female employment in Europe. Washington, D.C.: International Monetary Fund. (IMF Working Paper, European Department WP/16/49).

Esping-Andersen, G. (1990). The three worlds of welfare capitalism. New Jersey: Princeton University Press.

European Commission (2014). The 2015 Ageing Report: Underlying assumptions and projection methodologies. Brussels: European Commission, Directorate-General for Economic and Financial Affairs. (European Economy, 8/2014).

Heckman, J. and Jacobs, B. (2010). Policies to create and destroy human capital in Europe. Cambridge: National Bureau of Economic Research. (NBER Working Paper No. 15742).

ILO (1982). Resolution concerning statistics of the economically active population, employment, unemployment and underemployment. Adopted by the Thirteenth International Conference of Labour Statisticians, Geneva, October 1982.

Loichinger, E. (2015). Labor force projections up to 2053 for $26 \mathrm{EU}$ countries by age, sex, and highest level of educational attainment. Demographic Research 32(15): 443-486. doi:10.4054/DemRes.2015.32.15.

OECD (2013). Education at a glance 2013: OECD indicators. Paris: OECD Publishing.

Pissarides, C., Garibaldi, P., Olivetti, C., Petrongolo, B., and Wasmer, E. (2005). Women in the labour force: How well is Europe doing? In: Boeri, T., Del Boca, D., and Pissarides, C. (eds.). Women at work: An economic perspective. Oxford: Oxford Uni- 
Loichinger \& Prskawetz: Changes in economic activity: The role of age and education

versity Press: 7-120.

Prskawetz, A., Zagaglia, B., Fent, T., and Skirbekk, V. (2005). Decomposing the change in labour force indicators over time. Demographic Research 13(7): 163-188. doi:10.4054/DemRes.2005.13.7.

Steiber, N. and Haas, B. (2012). Advances in explaining women's employment patterns. Socio-Economic Review 10: 343-367. doi:10.1093/ser/mwr039.

UNESCO (2006). International standard classification of education. ISCED 1997. (May 2006, re-edition).

Vaupel, J. and Canudas Romo, V. (2002). Decomposing demographic change into direct vs. compositional components. Demographic Research 7(1): 1-14. doi:10.4054/ DemRes.2002.7.1. 


\section{Appendix}

Figure A-1: Country-specific labor force participation rates (in \%), by age groups and sex, 2000 and 2013
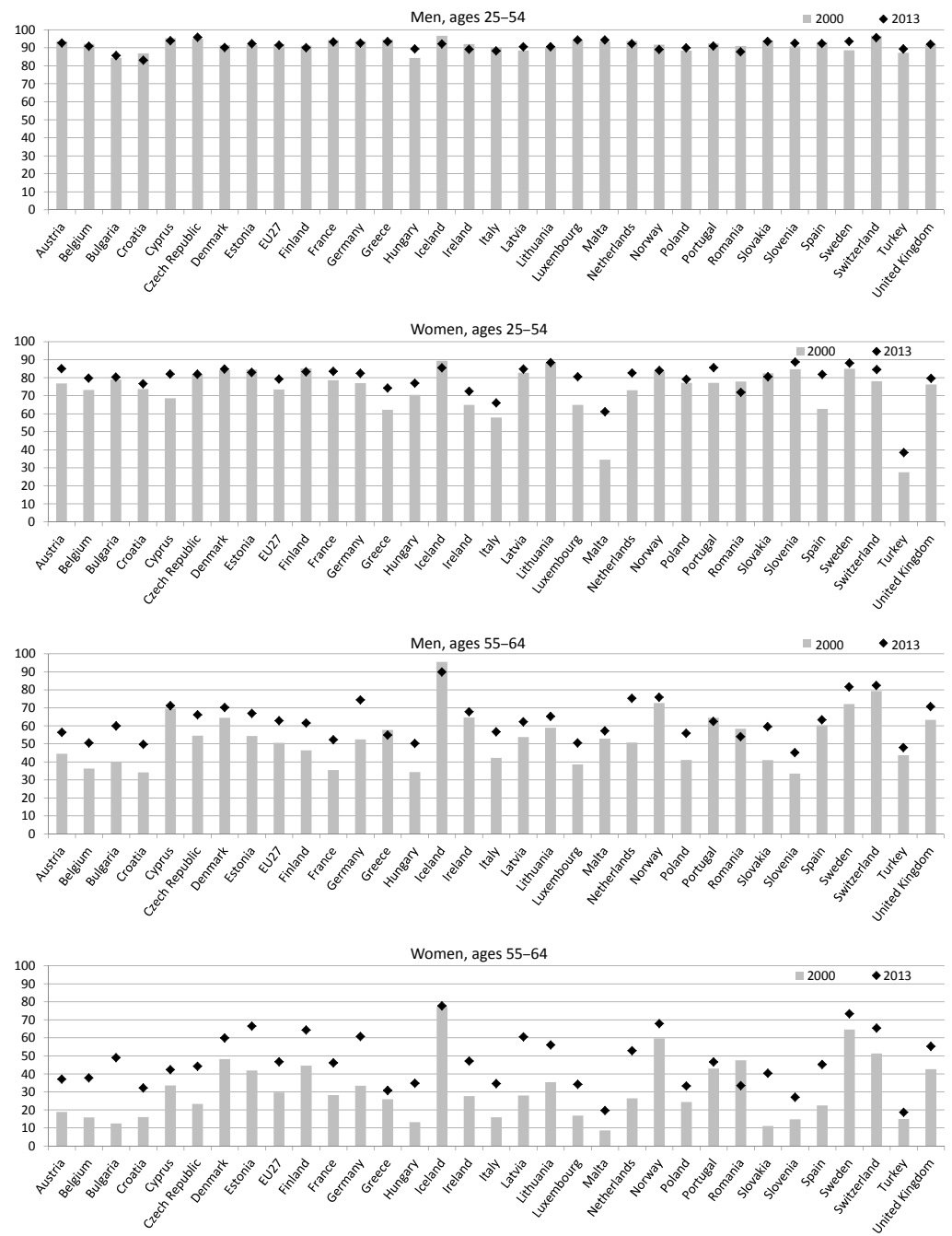

Source: Eurostat database, LFS-based. 
Loichinger \& Prskawetz: Changes in economic activity: The role of age and education

Figure A-2: $\quad$ Population by highest level of educational attainment, ages 55-59, by sex, 2000 to 2013
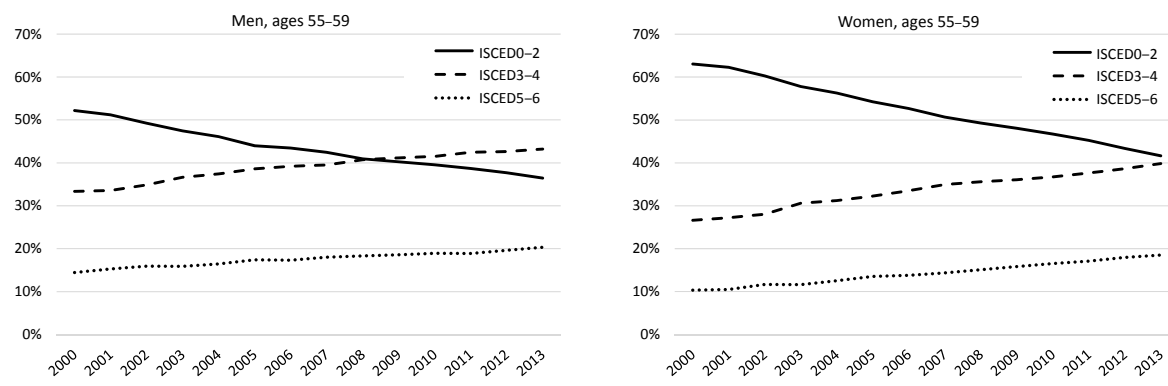

Source: Eurostat database, LFS-based.

Note: Countries included (unweighted average): Belgium, Czech Republic, Finland, France,Greece, Hungary, Italy, Netherlands, Portugal, Slovakia, Slovenia, Switzerland. 


\section{Figure A-3: $\quad$ Female crude labor force participation rates (in \%) for 14 selected countries, 1998 to 2013}
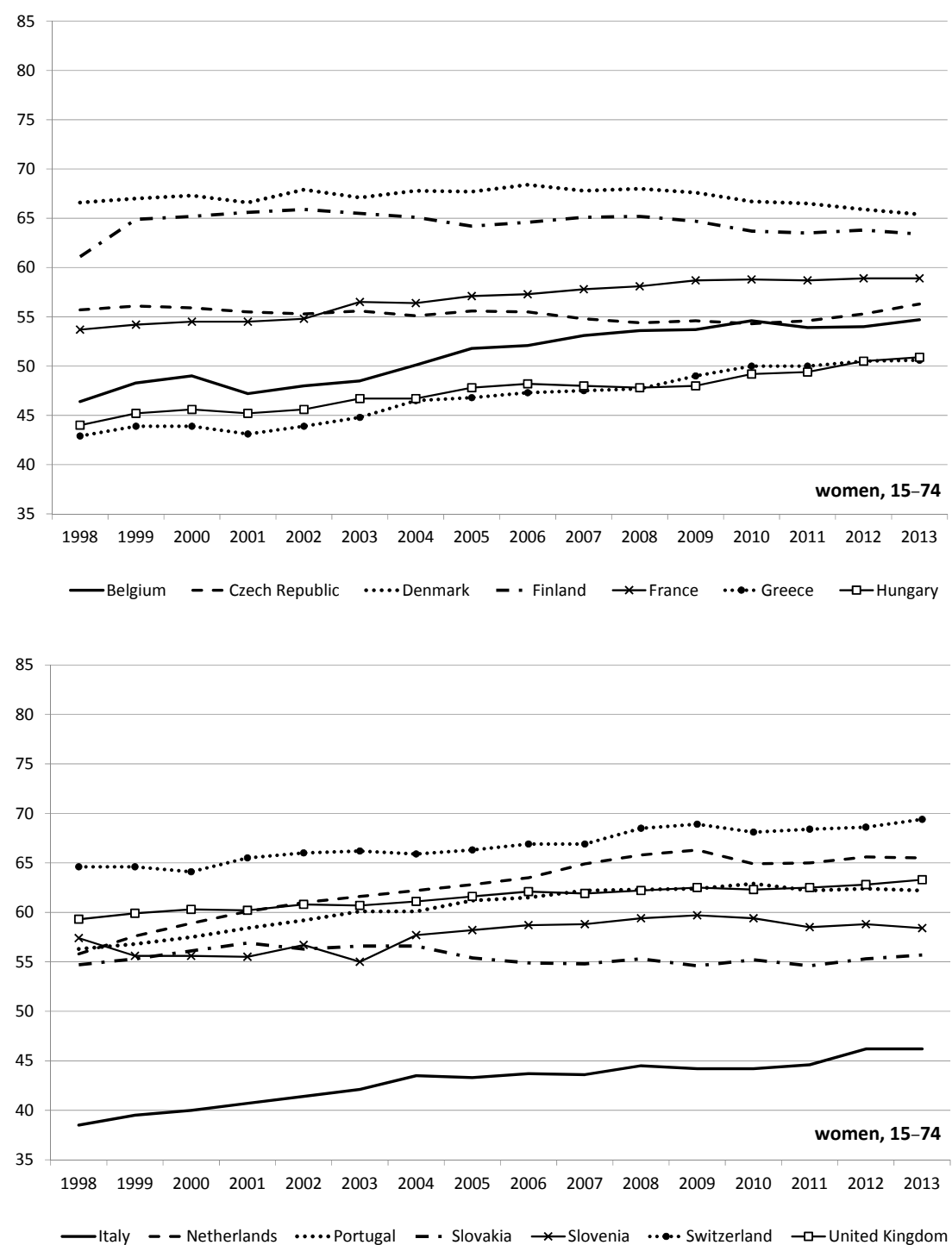

Source: Eurostat database. 
Loichinger \& Prskawetz: Changes in economic activity: The role of age and education

\section{Figure A-4: $\quad$ Male crude labor force participation rates (in \%) for 14 selected countries, 1998 to 2013}
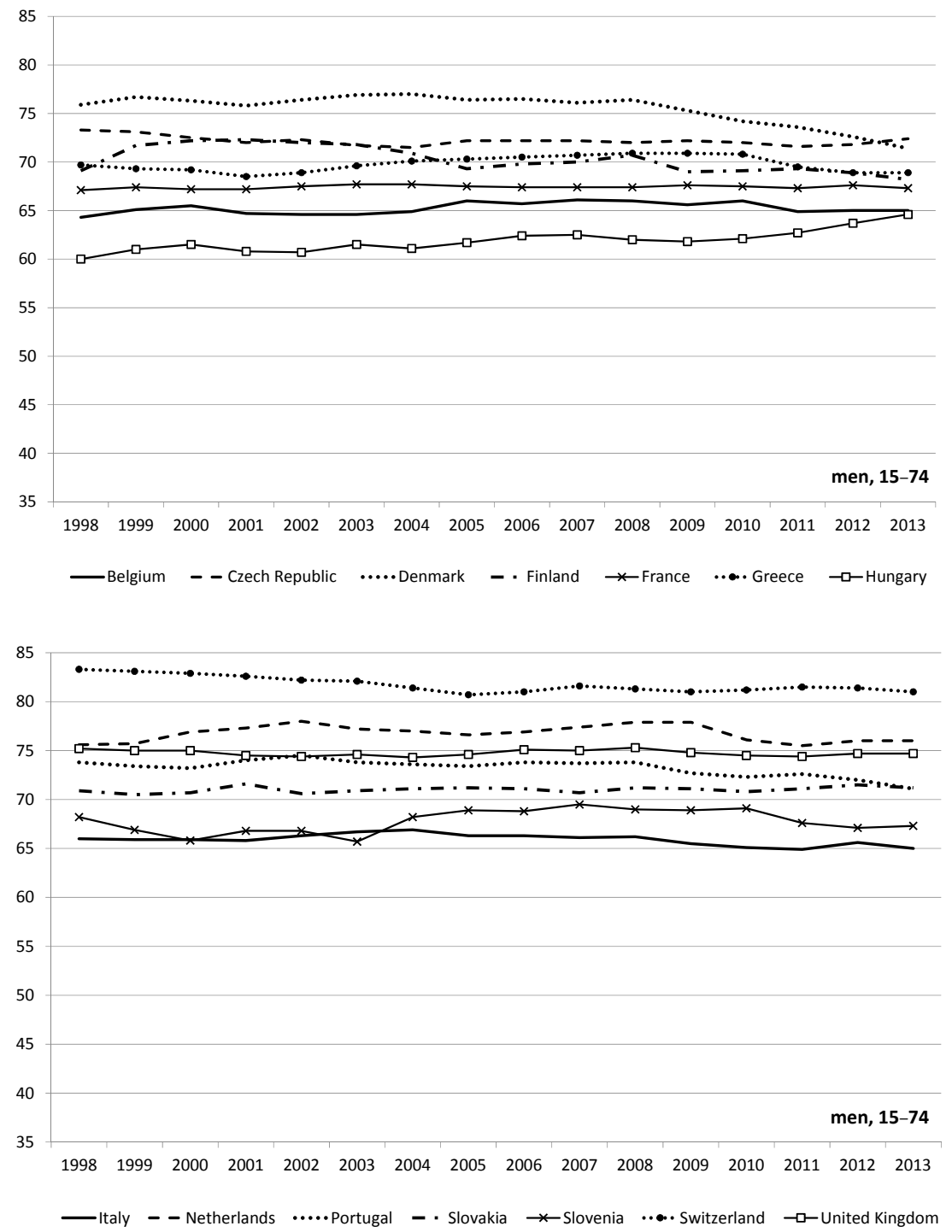

Source: Eurostat database. 